\title{
Anxiety, depression, health attitudes and coping strategies in doctors and teachers in a Cape Town setting
}

H van der Bijl, MMed (Psych), FCPsych (SA)

POosthuizen, MMed (Psych), FC Psych (SA), PhD

Department of Psychiatry, Stellenbosch University, Tygerberg, W Cape

Objective. To investigate two professional groups/doctors and teachers) with regard to symptoms of anxiety and depression as a measure of psychological distress, as well as perceptions regarding job satisfaction, workload and adequacy of remuneration. To assess health care behaviour as evidenced by substance use, psychotropic medication use, self-prescribing habits (in doctors), helpseeking behaviour as well as negative coping strategies as indicated by the intention to emigrate and/or leave the profession

Design. Data were collected from randomly distributed questionnaires which included a validated objective screening instrument, the Hospital Anxiety and Depression Scale (HADS)

Subjects and setting. Questionnaires were distributed among 260 physicians at Tygerberg Academic Hospital and 200 teachers from five different schools in the northern suburbs of metropolitan Cape Town.

Results. We found high levels of job dissatisfaction and symptoms of anxiety and depression in both groups, with teachers more affected than doctors. A large proportion of respondents with clinically significant levels of anxiety and depression remain untreated. Many respondents displayed a passive attitude with regard to seeking help. A significant proportion of doctors self-prescribed antidepressant and benzodiazepine medications. Only a small minority of doctors had a general practitioner whom they would consult when ill. Twenty-nine per cent of doctors indicated their intention to emigrate and $40 \%$ of teachers were planning to leave their profession.

Conclusion. Our results suggest that doctors and teachers in South Africa are two professional groups at high risk for developing serious mental health problems, with low levels of recognition and intervention at present.
A large body of evidence from First-World countries indicates an alarming trend of increasing incidence of mental health problems in physician populations. ${ }^{1.5}$ Associated are high prevalence rates of substance abuse and poor health outcomes in general. Evidence seems irrefutable that doctors have suicide rates well in excess of the general population. ${ }^{6-10}$ Yet doctors continue to display poor health care behaviour. The problem of increasing stress and its toll on doctors continues to be underrecognised, not only by doctors themselves, but by the community at large. Similar trends have been described for teacher populations indicating a high incidence of 'burnout' syndromes often resulting in poor health outcomes and early retirement.

Compared with the number of studies in First-World countries there appears to be little interest in or literature on the topic of mental health in these two professional populations in southern Africa and the rest of Africa. This is so despite the very real and different challenges doctors and teachers have to face here, including the HIV/AIDS pandemic and other economic, social and political factors that directly influence physicians and teachers as well as the health and education sectors they serve.

From media and other reports it is evident that many doctors and teachers are either leaving their profession or, even more commonly, leaving the country to seek greener pastures. ${ }^{11,12}$ The reported high rate of temporary and/or permanent emigration might be one of the symptoms of stress experienced by the medical and teaching professions.

The purpose of this study was to assess the levels of anxiety and depression in doctors and teachers in the northern suburbs of Cape Town and to seek correlations with perceptions of workload, remuneration and job satisfaction.

\section{Method}

Self-rating questionnaires were distributed to all the teachers at five different schools in the northern suburbs of Cape Town and to a sample of 260 physicians at Tygerberg Hospital during the period July 2003 - November 2003. As we anticipated a lower response rate from doctors we recruited a larger sample, representing approximately half the physicians at Tygerberg Hospital. The randomisation was done by means of a computergenerated randomisation table. 
Physicians and teachers were selected for a variety of reasons. They share a geographical area of residence and were expected, by and large, to have similar socio-economic and racial/cultural characteristics. Both these professions are involved in dealing daily and directly with people, and by working in the public sector they may be subjected to similar situations with regard to remuneration, resources, facilities, working conditions, etc. They have had to face significant challenges in recent years, e.g. changes in the school curriculum for teachers (viz. outcomes-based education), the introduction of community service for doctors; the impact of HIV/AIDS on the health system, redistribution of state funds to primary care facilities or previously underprivileged communities, and the effects of increasing violence in the community and possibly in the workplace.

Each subject received a bilingual (English/Afrikaans) questionnaire, and a letter explaining the purpose of the study and assuring anonymity. The questionnaire consisted of five parts: (i) demographic and descriptive data; (ii) the Hospital Anxiety and Depression Scale (HADS); (iii) questions on substance use; (iv) questions on health behaviour; and ( $v$ ) space for additional comment.

The HADS is a short, reliable, valid and easyto-use screening instrument for the detection of anxiety and depressive symptoms. ${ }^{13-15}$ The scale produces a total score and a subscale score for anxiety and depression, respectively. The aim of this study was not so much to diagnose an anxiety or depressive disorder, but to measure levels of distress as reflected by scores on the anxiety and depressive subscales. Total scores were therefore interpreted as an indication of severity of distress and categorised into groups, viz. 'No significant symptoms', 'Mild symptoms', 'Moderate symptoms' and 'Significant symptoms'. All data were entered into a Statistica (Statsoft Inc.) database. Much of the data were descriptive in nature, and are presented (where appropriate) as mean ( \pm standard deviation (SD)). Where categorical variables were compared, we used the chi-square $\left(\chi^{2}\right)$ test. Correlations between numerical data were analysed using Spearman's rank order correlation coefficient. A significance level of 0.05 was used throughout.

\section{Results}

A response rate of $88.5 \%$ was obtained from the teachers; this was regarded as representative for the schools included in our survey. A response rate of $51.9 \%$ was obtained from the doctors. For the whole group the response rate was $67.8 \%$. There were 312 subjects in total, consisting of 134 males and 178 females. The teacher group consisted of 57 males and 120 females and the doctor group consisted of 77 males and 58 females.
As measured by the HADS, significantly more teachers than doctors reported symptoms of anxiety and depression. Only $24 \%$ of teachers, compared with $47 \%$ of doctors, could be regarded as free of symptoms. This difference was statistically significant $\left(\chi^{2}=19.14, d f=1, p<0.001\right)$.

Twelve per cent of the teachers reported marked symptoms of anxiety/depression, 33\% had moderate symptoms, 31\% had mild symptoms and $24 \%$ had no symptoms. Therefore more than 1 in 10 teachers had clinically severe levels of anxiety and depression and almost half of all teachers had at least moderate symptoms. Doctors appeared to have fewer symptoms of anxiety/ depression, with only $2 \%$ reporting severe symptoms, $21 \%$ having moderate symptoms, and $30 \%$ having mild symptoms; $47 \%$ could be regarded as symptom free.

In the group as a whole females were significantly more likely to report symptoms of anxiety and depression, with $76 \%$ of women reporting at least mild symptoms of anxiety and depression compared with $52 \%$ of males $\left(\chi^{2}=19.90, d f=1, p<0.001\right)$. The gender difference was also statistically significant within the teacher subgroup, with $80 \%$ of females having at least mild symptoms compared with $67 \%$ of male teachers $\left(\chi^{2}=4.29\right.$, df $=$ $1, p=0.038)$. This gender difference was even more significant among the doctors, with $67 \%$ of females reporting symptoms compared with $42 \%$ of males $\left(\chi^{2}=8.75, d f=1, p=0.003\right)$.

\section{Perceptions of workload and job satisfaction}

Although the majority of subjects in both groups felt overworked, significantly more teachers than doctors felt this way $-83 \%$ of teachers compared with $63 \%$ of doctors $\left(\chi^{2}=17.28, d f=1, p<\right.$ 0.0011 . Of the whole group, $75 \%$ felt overworked.

Within the whole group, females were significantly more likely to feel overworked than males. Whereas $35 \%$ of males did not consider themselves to be overworked, only $18 \%$ of females felt this way $\left(\chi^{2}=11.82, d f=1, p=0.001\right)$. This difference was largely explained by differences in the teacher group, with almost $90 \%$ of female teachers perceiving themselves to be overworked compared with $71 \%$ of male teachers $\left(\chi^{2}=8.38, d f=1, p=\right.$ $0.004)$. In the doctor group $67 \%$ of females felt overworked and $60 \%$ of males felt overworked, but this did not reach statistical significance $\left(\chi^{2}=.798, d f=1, p=0.372\right)$. From the written comments it was evident that females from both occupational groups felt the strain of combining family life with a career.

Teachers were far more likely to have children than doctors. Sixtyseven per cent of teachers had children compared with $44 \%$ of doctors. This difference is highly significant $\left(\chi^{2}=16.45, \mathrm{df}=\right.$ $1, p<0.0011$ and was largely explained by the differences in 
female reproductive patterns between the two professions. Of female teachers, $67 \%$ had children, whereas only $28 \%$ of female doctors had children $\left(\chi^{2}=24.04, d f=1, p<0.001\right)$.

Despite both groups indicating excessive workload, the majority (77\%) still indicated feeling satisfied with their jobs. Doctors were significantly more likely to indicate satisfaction with their jobs than teachers, with $73 \%$ of teachers being satisfied with their jobs compared with $83 \%$ of doctors $\left(\chi^{2}=4.43, d f=1, p=0.035\right)$.

Again, in the whole group, females were significantly more likely to be dissatisfied with their jobs than males $-29 \%$ of females as compared with $15 \%$ of males $\left(\chi^{2}=8.19\right.$, $\left.d f=1, p=0.004\right)$. In the group of teachers, it was clearly evident that female teachers were significantly more likely to be dissatisfied with their jobs $-32 \%$ of female teachers versus $18 \%$ male teachers $\left(\chi^{2}=\right.$ $3.90, d f=1, p=0.048$ ) whereas in the doctor population the difference did not reach statistical significance $\left(\chi^{2}=2.08\right.$, df $=1, p=0.1491$.

\section{Perceptions regarding adequacy of remuneration}

The majority of subjects in both groups indicated that they felt underpaid. However, significantly more teachers (90\%) than doctors (75\%) felt this way $\left(\chi^{2}=13.596, d f=1, p<0.001\right)$. Interestingly, there was no gender difference $(p=0.517)$.

\section{Substance use}

Although relatively small numbers of subjects in both professional groups reported that they were smokers, the number of smokers in the teachers group was significantly higher, with $17 \%$ of teachers smoking compared with only $7 \%$ of doctors $\left(\chi^{2}=6.24, d f=1\right.$ $p=0.013)$. There was not a significant gender difference in number of smokers.

Both groups were equally likely to use alcohol to relieve symptoms of anxiety and depression - $16 \%$ of teachers and $15 \%$ of doctors admitted to using alcohol as a way of dealing with psychological distress $\left(\chi^{2}=0.14, d f=1, p=0.706\right)$. There was no significant gender difference in this regard $\left(\chi^{2}=2.43, d f=1, p=0.119\right)$. In the whole group, $36 \%$ indicated that they were teetotallers, $58 \%$ used $1-14$ units of alcohol per week, $4 \%$ used $15-21$ units, and only $2 \%$ indicated using 22 - 28 units per week. No respondents admitted to using in excess of 29 units of alcohol per week.

\section{Health care behaviour}

When asked whether they had a GP whom they consulted when ill, we found a very significant difference between the two professions. Almost $90 \%$ of teachers had a GP, in striking contrast to the mere $12 \%$ of doctors $\left(\chi^{2}=186.07, d f=1, p<0.001\right)$. In the whole group, females were significantly more likely to have a GP, viz. $66 \%$ of females compared with $43 \%$ of males (X2 = 16.67, $d f=1, p<0.0011$. There was no significant gender difference within the teachers group $190 \%$ of both males and females had a GP). Although the numerical difference among doctors was far greater, on its own this did not reach statistical significance. Only $8 \%$ of male doctors had a GP compared with $17 \%$ of female doctors $\left(\chi^{2}=2.83, \mathrm{df}=1, p=0.093\right)$.

As could be expected from the results above, a greater number of teachers visited their GP within the last year - on average 79\% of teachers compared with $15 \%$ of doctors $\left(\chi^{2}=125.87, \mathrm{df}=\right.$ $1, p<0.0011$. Despite this, there was no significant difference in the number of sick leave days taken between the groups. Respondents from both occupational groups took surprisingly little sick leave given the high rates of reported dissatisfaction, feelings of being overworked and symptoms of anxiety and depression. Fifty-eight per cent of teachers and $64 \%$ of doctors had not been off sick a single day in the previous year. Thirty-nine per cent of teachers and $28 \%$ of doctors had taken between 1 and 5 days sick leave. Only $2 \%$ of teachers and $6 \%$ of doctors took between 6 and 10 days and less than $2 \%$ in both groups had taken more than 20 days' sick leave in the previous year.

\section{Help-seeking behaviour}

We found that a significantly larger number of teachers would take a passive 'wait-and-see' attitude in the case of possible depression or emotional problems - $32 \%$ of teachers indicated a passive 'wait-and-see' attitude in the case of possible depression or emotional problems, compared with $17 \%$ of doctors $1 \chi^{2}=$ 8.81, $d f=1, p=0.0031$. In addition, a significant number (13\%) of doctors indicated that they would treat themselves. Only $4 \%$ of doctors said they would visit a GP as a first line of action, $6 \%$ said they would speak to a colleague but treat themselves, $27 \%$ said they would see a psychiatrist, and 10\% reported that they would see a psychiatrist but still treat themselves!

\section{Self-prescribing habits among doctors}

One in 10 doctors indicated self-prescription of antidepressants over the past 5 years, with almost the same number prescribing benzodiazepines for themselves. Teachers were significantly more likely to have used psychotropic (antidepressant or anxiolytic/ hypnotic) medication in the past 5 years. Thirty-five per cent of teachers compared with $17 \%$ of doctors reported use of psychotropic medication $\left(\chi^{2}=12.73, \mathrm{df}=1, p<0.001\right)$. 


\section{Intention to leave the profession orthe country}

A significantly higher proportion of doctors compared with teachers reported the intent to leave the country. In fact, only $11 \%$ of teachers indicated an intention to emigrate compared with almost $30 \%$ of doctors $\left(\chi^{2}=16.29, d f=1, p<0.001\right)$. Despite gender differences with regard to symptoms of anxiety and depression, perceptions of job satisfaction and workload, there was no gender difference in subjects' intention to leave South Africa $\left(\chi^{2}=0.37, d f=1, p=0.543\right)$.

In contrast, a significantly higher proportion of teachers indicated an intention to leave their profession compared with doctors $140 \%$ v. $10 \%, \chi^{2}=35.85, d f=1, p<0.001$ ). In the whole group, 33\% of females said they were planning to leave their jobs compared with $19 \%$ of males $\left(\chi^{2}=7.93, d f=1, p=0.005\right)$. Although the number of female teachers intending to leave their profession was greater than the number of males $135 \%$ of males versus $42 \%$ of females), this did not reach statistical significance $\left(\chi^{2}=0.84\right.$, df $=1, p=0.357)$. This was also true in the case of doctors, with $14 \%$ of females intending to leave their job compared with $6 \%$ of males $\left(\chi^{2}=2.03, d f=1, p=0.155\right)$

\section{Disc ussion}

Although it may be controversial to compare different professional groups, we believe that it provides important information on the state of the professions in our area and serves to highlight certain common themes and problem areas. In our study population, but probably in South Africa in general, doctors and teachers are two professional groups at high risk for developing serious mental health problems. Our results could mislead the reader into believing that doctors do not have significant problems with anxiety or depression, yet the truth is that although symptoms were less prevalent than among teachers, at least 1 out of every 5 doctors had at least moderate symptoms of anxiety or depression.

Symptoms of anxiety and depression appeared to be related to job dissatisfaction, work overload and inadequacy of remuneration. Females in both groups had higher rates of symptoms of depression and anxiety, perception of work overload and job dissatisfaction.

Several studies, 16-18 have shown that stress and depression levels among female doctors are considerably higher than those of other professional women and of male doctors. In addition, female doctors in general are reported to have suicide rates up to four times those of their peers. ${ }^{7}$ From our study it would appear that the same might be true for female teachers. However no mental health studies have been done on teachers in South Africa, and very few such studies have been done elsewhere in the world. It appears that suicide trends among teachers have not been studied much.

The most frequently cited stressor for female doctors is the conflict between their careers and their personal lives, and this stressor has been strongly linked to depression. Female doctors have a higher divorce rate than male doctors and fewer children. This may indicate a belief that it is easier to change one's marital state or limit one's family than to succeed in challenging the accepted career path.

The high rates of depression/anxiety symptoms among teachers, specifically female teachers, are cause for considerable concern and call for further study. Our study was not designed to specifically identify causes of stress in either teachers or doctors. However, based on feedback from the questionnaires, female teachers indicated that it was very difficult trying to balance family life and a career.

Most teachers had classes of 30 - 40 pupils and a fair number of teachers had classes in excess of 40 pupils. Judging from their comments, many teachers perceived pupils to have become increasingly unruly, rude and ill mannered. They also expressed the opinion that there are no adequate measures in place to enforce discipline, which left them feeling disempowered, frustrated and even abused. Without exception, teachers were very negative towards and dissatisfied with the system of outcomes-based education (OBE). In general they expressed the view that it was an unworkable system that had increased their workload significantly without the prospect of improved results. Frustration was directed at the Department of Education and there was a perception that the latter was not in touch with what was happening at ground level.

Despite working in different hospital departments and at different levels of appointment, it was evident from the additional comments that doctors reported very similar causes of stress. The overwhelming and recurring themes were the severe burden of workload with too little time to give quality service. Lack of hospital equipment and supplies, reduced budgets, low staffing levels and inadequacy of theatre time as well as constantly overbooked clinics were reported by most doctors. At the same time doctors expressed their frustration at the Provincial Government of the Western Cape for lack of support and inadequate salaries. 
Health behaviour in both occupational groups should be cause for concern. A significant proportion of respondents displayed a passive attitude with regard to help-seeking in the case of a psychiatric or emotional problem. Given the reported rates for symptoms of anxiety/depression (teachers: 12\% with marked symptoms of anxiety/depression and 33\% with moderate symptoms; doctors: $2 \%$ with severe symptoms, $21 \%$ with moderate symptoms), this probably indicates that a noteworthy proportion of respondents have potentially clinically significant levels of anxiety and depressive symptoms, but remain untreated. Furthermore, a significant number of doctors are treating themselves with antidepressant and benzodiazepine medications.

Only a small minority of doctors (12\%) had their own GP to consult when ill. By implication the majority are treating themselves, confirming the inappropriate health care behaviour observed universally among physicians. However, this seems to be much worse in our study population as a recent Australian survey ${ }^{5}$ considered their findings to be of concern compared with other First-World countries $-42 \%$ of their doctors had their own GP.

Interestingly there was no significant difference in the number of sick leave days taken between doctors and teachers and it would appear that both these professional groups have admirable work ethics given the stresses they are subjected to on a daily basis. It can, however be hypothesised that this tendency to take little sick leave might be influenced by lack of arrangement in the state service for a substitute/locum teacher or doctor in the case of absence. Equally strained colleagues would therefore have to bear the additional burden. The pressure of not being able or willing to take sick leave, even when this might be perfectly justifiable, could possibly add additional strain and dissatisfaction, resulting in a vicious circle.

When we compared our results with those of other studies investigating substance use in different populations of doctors, 19,20 we found the extremely low reported rate of alcohol abuse both surprising and rather difficult to accept. Most other studies indicate prevalence rates of excessive alcohol use in doctors to be between $40 \%$ and $60 \%$.

Fear of being identified in some way may have led to underreporting of excessive alcohol use. The lower rate of smoking in doctors might arguably be related to greater awareness of the health risks involved and seeing patients daily who suffer from the consequences of smoking.

One can only speculate about the suicide tendencies in South African doctor and teacher populations, given our results and indications of poor health care behaviour in both groups. Efforts by the investigator ( $H v d B)$ to obtain statistics on the incidence of suicide among doctors in South Africa were fruitless.

The tendency of doctors to neglect their own health care seems universal but is possibly particularly pronounced among South African doctors. The reasons for this phenomenon have been explored to some extent by other authors and as Lawrence' states, many among the medical profession and society in general still ascribe to the notion that doctors are not at risk from stress, that doctors don't get sick, and if they do, help is readily available free of charge.

'This delusion that we are "doctors" and not people "whose occupation is doctoring" has been gladly accepted by the public, by government and the media, including medical media. A mystification process has produced a stereotype that is impossible to attain and marginalized the real, imperfect, vulnerable men and women whose job is doctoring. By taking the mantle of "doctor" we deny the life problems of our age group in home and family living, personal development, enjoyment of leisure, community living as well as health. We only exist within career and vocation.

'Yet, doctors and others working in caring professions are at risk of "burnout" - the symptoms of which include: Fatigue, emotional exhaustion, apathy, cynicism, irritability, anger, avoidance behavior, indecision and inefficiency. This may be complicated by self-medication with alcohol and other drugs.

Medical education, from undergraduate level onwards, should aim to modify the medical culture which pressurises doctors into believing that they should never be sick, or at least that they should never complain or seek help. Skills to treat colleagues should be integral to medical education.

The British Medical Association has produced a prescriptive set of ethical responsibilities of doctors towards themselves and their families, and also of doctors towards colleagues as patients. It is imperative that a similar set of guidelines be adopted in this country.

It has to be stressed that our study population could probably be considered a relatively affluent and privileged group compared with other geographical areas and settings in South Africa. Although there are clear limitations to comparing with potentially different groups and in generalising the findings of a localised study, our results were still alarming and seem to confirm media reports of increasing dissatisfaction among professional groups and the trend of mass emigration. One can only speculate at this stage about the situation among less-privileged groups of doctors and teachers in South Africa. 
Unless the stressors causing dissatisfaction and possible mental health problems in both of these two essential professional groups are identified and addressed, both the health and educational sectors might be facing a bleak future.

\section{References}

1. Lawrence JM. Stress and the doctor's health. Aust Fam Physician 1996; 25: 1249 1256

2. Newbury-Birch D, Kamali F. Psychological stress, anxiety, depression, job satisfaction, and personal characteristics in pre-registration house officers. Postgrad Med J 2001 ; 77. $109-11$.

3. Caplan RP. Stress, anxiety, and depression in hospital consultants, general practitioners and senior health managers. BMJ 1994; 309: 1261-1263.

4. Cooper $\mathrm{CL}$, Rout $U$, Faragher $B$. Mental health, job satisfaction, and job stress among general practitioners. BMJ 1998; 298: 366-370.

5. Parsons J. Are doctors immune to depression? Aust Fam Physician 200 1; 30: 225 231

6. Schlicht S, Gordon I, Ball JR, et al. Suicide and related deaths in Victorian doctors. Med J Aust 1990; 153: 518-521

7. Lindeman $S$, Laara $E$, Hakko $H$, Lonnqvist J. A systematic review on gender-specific suicide mortality in medical doctors. BrJ Psychiatry 1996; 168: 274-279.

8. Holmes VF, Rich CL. Suicide among physicians. In: Blumenthal SJ, Kupfer DJ, eds. Suicide Over the Life Cycle: Risk Factors, Assessment, and Treatment of Suicidal Patients. Washington, DC: American Psychiatric Press, 1990: 599-618
9 Frank E, Dingle AD Self-reported depression and suicide attempts among US women physicians. Am J Psychiatry 1999; 156: 1887-1894

10. Arnetz BB, Horte L, Hedberg A, et al. Suicide patterns among physicians related to other academics as well as to the general population: Results from a national longterm prospective study and a retrospective study. Acta Psychiatr Scand 1987: 75: 139 143

1 1. Bateman C. Deans ponder skills drain. S Afr Med J 200 1; 91 : 544-545

12. McClelland C. South African brain drain costing 5 billion - and counting. J Can Med Ass 2002; 167: 793

13. Zigmond AS, Snaith RP. The hospital anxiety and depression scale. Acta Psychiat Scand 1883; 67: 361-363

14. Aylard PR, Gooding JH, McKenna PJ, Snaith RP. A validation study of three anxiety and depression self-assessment scales. I Psychosomatic Research 1987: 1:261268.

15. Bramley PN, Easton AME, Morley S, Snaith RP. The differentiation of anxiety and depression by rating scales. Acta Psychiatr Scand 1988; 77: 133-138.

16. North CS, Ryall JE Psychiatric illness in female physicians. Are high rates of depression an occupational hazard? Postgrad Med 1997; 101: 233-242

17. Welner A, Marten S, Wochnick R, et al. Psychiatric disorders among professional women. Arch Gen Psychiatry 1979: 36: 169-173.

18. Firth-Cozens !. Sources of stress in women junior house officers. BMJ 1990: 234 992-993.

19. McAuliffe WE, Rohman $M$, Breer $P$, et al. Alcohol use and abuse in random samples of physicians and medical students. Am J Public Health 1991; 81: 177-182.

20. Birch $D$, Ashton $H$, Kamali F. Alcohol, drinking, illicit drug use and stress in junior house officers in north-east England. Lancet 1998; 352: 785 